\title{
openheart Risk of cardiac manifestations in adult mitochondrial disease caused by nuclear genetic defects
}

\author{
Albert Zishen Lim (10 , ${ }^{1,2}$ Daniel M Jones, ${ }^{1}$ Matthew G D Bates, ${ }^{3}$ \\ Andrew M Schaefer, ${ }^{1,2}$ John O'Sullivan, ${ }^{4}$ Catherine Feeney, ${ }^{1,2}$ Maria E Farrugia, ${ }^{5}$ \\ John P Bourke, ${ }^{4}$ Doug M Turnbull, ${ }^{1,2}$ Gráinne S Gorman (D) ,1,2 \\ Robert McFarland (D) , ${ }^{1,2}$ Yi Shiau $\mathrm{Ng}$ (D) ${ }^{1,2}$
}

To cite: Lim AZ, Jones DM, Bates MGD, et al. Risk of cardiac manifestations in adult mitochondrial disease caused by nuclear genetic defects. Open Heart 2021;8:e001510. doi:10.1136/ openhrt-2020-001510

Received 9 November 2020 Revised 18 January 2021 Accepted 5 February 2021

\section{Check for updates}

(c) Author(s) (or their employer(s)) 2021. Re-use permitted under CC BY. Published by BMJ.

${ }^{1}$ Wellcome Centre for Mitochondrial Research, Translational and Clinical Research Institute, Newcastle University, Newcastle upon Tyne, UK

${ }^{2}$ NHS Highly Specialised Service for Rare Mitochondrial Disorders, Newcastle Upon Tyne Hospitals NHS Foundation Trust, Newcastle Upon Tyne, UK ${ }^{3}$ Department of Cardiology, James Cook University Hospital, Middlesbrough, UK

${ }^{4}$ Cardiology, Freeman Hospital Cardiothoracic Centre, Newcastle upon Tyne, UK ${ }^{5}$ Queen Elizabeth University Hospital, Institute of Neurological Sciences, Glasgow, UK

Correspondence to Dr Yi Shiau Ng; yi.ng@ncl.ac.uk

\section{ABSTRACT}

Objective Regular cardiac surveillance is advocated for patients with primary mitochondrial DNA disease. However, there is limited information to guide clinical practice in mitochondrial conditions caused by nuclear DNA defects. We sought to determine the frequency and spectrum of cardiac abnormalities identified in adult mitochondrial disease originated from the nuclear genome. Methods Adult patients with a genetically confirmed mitochondrial disease were identified and followed up at the national clinical service for mitochondrial disease in Newcastle upon Tyne, UK (January 2009 to December 2018). Case notes, molecular genetics reports, laboratory data and cardiac investigations, including serial electrocardiograms and echocardiograms, were reviewed.

Results In this cohort-based observational study, we included 146 adult patients (92 women) (mean age $53.6 \pm 18.7$ years, $95 \% \mathrm{Cl} 50.6$ to 56.7 ) with a mean follow-up duration of $7.9 \pm 5.1$ years $(95 \% \mathrm{Cl} 7.0$ to 8.8$)$. Eleven different nuclear genotypes were identified: TWNK, POLG, RRM2B, OPA1, GFER, YARS2, TYMP, ETFDH, SDHA, TRIT1 and AGK. Cardiac abnormalities were detected in 14 patients $(9.6 \%)$. Seven of these patients $(4.8 \%)$ had early-onset cardiac manifestations: hypertrophic cardiomyopathy required cardiac transplantation (AGK; $\mathrm{n}=2 / 2$ ), left ventricular (LV) hypertrophy and bifascicular heart block (GFER; $\mathrm{n}=2 / 3$ ) and mild LV dysfunction (GFER; $\mathrm{n}=1 / 3$, YARS2; $\mathrm{n}=1 / 2, T W N K ; \mathrm{n}=1 / 41)$. The remaining seven patients had acquired heart disease most likely related to conventional cardiovascular risk factors and presented later in life $(14.6 \pm 12.8$ vs $55.1 \pm 8.9$ years, $\mathrm{p}<0.0001$ ).

Conclusions Our findings demonstrate that the risk of cardiac involvement is genotype specific, suggesting that routine cardiac screening is not indicated for most adult patients with nuclear gene-related mitochondrial disease.

\section{INTRODUCTION}

Mitochondrial diseases are a group of neurometabolic disorders that can be caused by genetic defects in both the mitochondrial DNA (mtDNA) and nuclear DNA (nDNA). The estimated prevalence of all forms of adult mitochondrial disease is 1 in 4300 , of

\section{Key questions}

What is already known about this subject?

- Approximately one-third of adult patients with mitochondrial disease have nuclear gene inheritance (ie, nuclear gene defect).

- Regular cardiac surveillance is currently advocated for these patients based on the experienced derived from the management of primary mitochondrial DNA disorders.

What does this study add?

- In this observational cohort study $(n=146)$, we show that the majority of adult patients with mitochondrial disease of the nuclear genome $(\sim 90 \%)$ have normal cardiac investigations, and the risk of cardiac involvement is genotype specific.

- Fourteen patients $(9.6 \%)$ developed cardiac abnormalities, but only half of them (4.8\%) were attributed to the mitochondrial dysfunction with a mean follow up of 8 years.

How might this impact on clinical practice?

- The risk of cardiac involvement is low in most adult patients with nuclear gene-related mitochondrial disease and we propose a cardiac algorithm to guide clinical practice.

which approximately a third of patients have nDNA pathogenic variants. ${ }^{1}$ Mitochondrial diseases are clinically heterogeneous and can affect organs with high-energy demand such as central nervous system, skeletal muscle and heart. ${ }^{2}$ The range of cardiac involvement such as hypertrophic cardiomyopathy, conduction abnormalities and sudden cardiac death are commonly reported in patients with certain forms of primary mtDNA disease. ${ }^{3-6}$ However, the spectrum of cardiac manifestation among patients with nDNA defects has only been described in isolated case reports or small case series. At present, regular cardiac surveillance is 
routinely recommended for all patients with mitochondrial disease irrespective of the underlying genetic aetiology. $^{8}$

A better understanding of cardiac abnormalities across different genotypes would guide clinicians to tailor cardiac surveillance to high-risk groups and instigate appropriate intervention at the earliest stage. On the other hand, patients with negligible risk of developing a cardiac disease related to the mitochondrial dysfunction can be reassured without requiring regular cardiac screening, potentially reducing the burden of healthcare cost. In this study, we sought to evaluate the cardiac phenotypes systematically in adult patients with mitochondrial disease resulting from pathogenic mutations in the nuclear genes. We also set out to determine the cardiac abnormalities that are attributed to their underlying primary mitochondrial disorders. To progress the current clinical practice towards individualised precision medicine, we aimed to identify patients who were most likely to benefit from regular cardiac screening in this study.

\section{METHODS}

\section{Study design and settings}

We identified adult patients harbouring pathogenic nDNA variants from the National Health Service Highly Specialised Service for Rare Mitochondrial Disorders in Newcastle upon Tyne, UK and Mitochondrial Disease Patient Cohort (MitoCohort, UK) (REC: 13/NE/0326), between January 2009 to December 2018. Children who succumbed to fatal cardiac disease had been excluded. These patients were regularly reviewed by clinicians with expertise in mitochondrial disease every 6-24 months (AZL, AMS, GSG, RM, DMT and YSN), and their disease burden, including the degree of cardiac disease severity, was assessed objectively using the Newcastle Mitochondrial Disease Adult Scale, a validated disease rating scale. ${ }^{9}$ Patients had undergone regular cardiac testing (ECG and/or echocardiogram) over a similar period. The abnormal cardiac findings were reviewed by the cardiologists with expertise in mitochondrial diseases, and patients were further assessed if clinically indicated (JPB, MGDB and JO). Demographic data, clinical phenotype, molecular genetic data and blood test results were derived from the MitoCohort. Other medical co-morbidities and drug history were obtained from the clinical notes where available. The majority of genetic diagnoses were achieved via the identification of mitochondrial dysfunction in muscle biopsies (such as large number of cytochrome c oxidase deficient fibres, presence of mtDNA rearrangement/multiple deletions and/or mitochondrial respiratory chain deficiency) and Sanger sequencing of candidates genes based on the clinical phenotype. Our diagnostic algorithm for the mitochondrial disease has been described elsewhere..$^{1011}$

\section{Defining cardiac abnormalities in mitochondrial disease}

Abnormal echocardiographic findings were reported according to the British Society of Echocardiography and European Society of Cardiology criteria. ${ }^{12-14}$ Left ventricular (LV) dysfunction was categorised into normal (left ventricular ejection fraction (LVEF) $>55 \%$ ), mild (LVEF 45\%-55\%), moderate (LVEF 35\%-44\%) and severe (LVEF $<35 \%)$. LV hypertrophy $(\mathrm{LVH})$ was defined as LV end diastolic septal thickness of $>12 \mathrm{~mm}$ in adults. Hypertrophic cardiomyopathy was clinically recognised by a maximal $\mathrm{LV}$ wall thickness $>15 \mathrm{~mm}$ in this population. The interpretation of ECG complied with consensus recommendations from professional bodies in clinical cardiology. ${ }^{15}$ Cardiovascular risk factors, as defined by established practice guidelines were ascertained namely, hypertension (persistent blood pressure $\geq 140 / 90 \mathrm{~mm}$ $\mathrm{Hg}$ ), diabetes mellitus, hypercholesterolaemia (serum cholesterol level $>5 \mathrm{mmol} / \mathrm{L}$ ), obesity (body mass index $>30$ ) and smoking status. ${ }^{16}$ Any cardiac findings with uncertain significance were adjudicated by the cardiologists (JPB, MGDB and JO).

\section{Patient and public involvement statement}

The patients and the public were not involved in the study design, recruitment, statistical analysis and writing of this study.

\section{Statistical analysis}

Statistical analyses were performed using IBM SPSS Statistics (V.24). The incidence rate in this study was expressed as the number of cardiac abnormalities detected per number of years experienced by the cohort at risk in person-years. ${ }^{17}$ Binominal outcome of cardiac investigations from each genotype underwent $\chi^{2}$ analysis, including, Fisher's exact test for counts $<5$ and parametric data were compared using analysis of variance that had been accounted for normality. Statistical significance was defined as $\mathrm{p} \leq 0.05$.

\section{RESULTS}

\section{Clinical phenotypes and genotypes}

We identified 146 adults with nDNA defects (92 women) who had complete clinical and cardiac data sets available for the analysis. The mean age of patients was $53.6 \pm 18.7$ years (95\% CI 50.6 to 56.7 ), and the mean follow-up (FU) duration was $7.9 \pm 5.1$ years $(95 \% \mathrm{CI} 7.0$ to 8.8 ). The common clinical features of mitochondrial disease were eyelid ptosis $(54.1 \%)$, chronic progressive external ophthalmoplegia (CPEO) (51.4\%), cerebellar ataxia $(34.2 \%)$, myopathy $(32.9 \%)$, gastrointestinal disturbance $(32.2 \%)$ and peripheral neuropathy $(22.6 \%)$ (table 1). Eleven nuclear gene defects were identified: $T W N K(\mathrm{n}=45), P O L G(\mathrm{n}=37), R R M 2 B(\mathrm{n}=24)$, OPA1 $(\mathrm{n}=24)$, GFER $(\mathrm{n}=3)$, YARS2 $(\mathrm{n}=2), \operatorname{TYMP}(\mathrm{n}=3)$, ETFDH $(\mathrm{n}=2), \operatorname{SDHA}(\mathrm{n}=2), \operatorname{TRIT1}(\mathrm{n}=2)$ and AGK $(\mathrm{n}=2)$. Clinical phenotypes associated with individual nuclear defects are summarised in online supplemental 
Table 1 Summary of the patient cohort with Mendelian mitochondrial disease $(n=146)$

\section{Demographic data}

\begin{tabular}{ll}
\hline No of patients & 146 \\
\hline Mean age (SD; 95\% Cl) & 53.6 years (18.8; \\
& $50.6-56.7)$ \\
\hline Mean duration of follow-up (SD; 95\% Cl) & 7.9 years $(5.1 ; 7.0-8.8)$ \\
Women (\%) & $92(63)$
\end{tabular}

\begin{tabular}{|lc|}
\hline Clinical features associated with mitochondrial disease \\
\hline Mean age of onset of mitochondrial disease & 29.0 years (19.8; \\
(SD; $95 \% \mathrm{Cl})$ & $25.4-32.6)$ \\
\hline Eyelid ptosis (\%) & $79(54.1)$ \\
\hline Progressive external ophthalmoplegia (\%) & $75(51.4)$ \\
\hline Cerebellar ataxia (\%) & $50(34.2)$ \\
\hline Myopathy (\%) & $48(32.9)$ \\
\hline Gastrointestinal disturbance (\%) & $47(32.2)$ \\
\hline Peripheral neuropathy (\%) & $33(22.6)$ \\
\hline Epileptic seizures (\%) & $7(4.8)$ \\
\hline Mean creatine kinase (SD; 95\% Cl) & 216 units/L (218; 171- \\
\hline Mean lactate (SD; 95\% Cl) & $261)$ \\
\hline
\end{tabular}

\section{Cardiovascular risk factors}

\begin{tabular}{|lc|}
\hline Systolic blood pressure mm Hg (SD; 95\% Cl) & $134(17.2 ; 130-138)$ \\
\hline Diastolic blood pressure mm Hg (SD; 95\% Cl) & $78(11.4 ; 76-81)$ \\
\hline Hypertension (\%) & $36(4.7)$ \\
\hline High cholesterol level >5 mmol/L (\%) & $29(19.9)$ \\
\hline Positive smoking history (\%) & $20(13.7)$ \\
\hline Body mass index kg/m² (SD; 95\% Cl) & $26.5(6.2 ; 25.1-27.9)$ \\
\hline Obesity $(\mathrm{BMl}>30)(\%)$ & $19(13.0)$ \\
\hline Diabetes $(\%)$ & $16(11.0)$ \\
\hline
\end{tabular}

The cardiovascular risk factors (hypertension, high cholesterol, smoking history, obesity and diabetes) reported were the minimum frequencies of this cohort based on available information. BMI, body mass index.

table. Three participants died during the FU (POLGsevere epileptic encephalopathy and multiorgan failure, ETFDH - respiratory failure secondary to neuromuscular weakness, TYMP—gastrointestinal sepsis); none of them manifested with any cardiac abnormalities.

\section{Cardiac abnormalities}

Of the 146 patients with complete clinical and cardiac datasets, the majority $(90.4 \%)$ had normal cardiac findings during the FU period. We only identified 14 cases with significant cardiac abnormalities $(9.6 \%)$ (figure 1) with an estimated incidence rate of 1.8 per 1000 personyears (95\% CI 1.1 to 3.1). Eight of the 14 patients developed LVH. Reduced LVEF was evident in ten patients: mild $(n=7)$, moderate $(n=1)$ and severe $(n=2)$. Cardiac conduction abnormalities electrical abnormalities were identified in seven $(4.8 \%)$ : Wolff-Parkinson-White
(WPW) syndrome $(\mathrm{n}=1)$, non-sustained ventricular tachycardia (VT) $(\mathrm{n}=1)$, persistent atrial fibrillation (AF) $(\mathrm{n}=1)$, left bundle branch block (LBBB) $(\mathrm{n}=2)$, bifascicular block $(\mathrm{n}=1)$ and asymptomatic QT prolongation (QT $c>500 \mathrm{~ms}) \quad(\mathrm{n}=1)$. Coexisting LV dysfunction was identified in the cases of WPW, non-sustained VT and persistent AF (figure 1).

Cardiac abnormalities were attributable to the underlying mitochondrial genotype in seven patients $(4.8 \%)$ : $\operatorname{AGK}(\mathrm{n}=2), \operatorname{GFER}(\mathrm{n}=3), \operatorname{YARS} 2(\mathrm{n}=1)$ and $T W N K(\mathrm{n}=1)$. The mean age of cardiac manifestation was $14.6 \pm 12.8$ years (95\% CI 2.74 to 26.4). Both patients (unrelated) who harboured pathogenic variants in $A G K$ presented with an infantile-onset ( $<1$ year old) hypertrophic cardiomyopathy, which progressed to end-stage cardiac failure. Both patients subsequently required LV assist device insertions, followed by orthotopic cardiac transplants at age 13 years. One of the $A G K$ cases also had symptomatic WPW syndrome and underwent two accessory pathway (AP) ablation procedures at age 4 years (left lateral AP) and 7 years (left posterolateral AP), respectively.

Two siblings with recessive GFER disease were identified to have LVH with preserved ejection fraction, and electrical abnormalities (bifascicular block and LBBB, respectively) in their twenties. The third patient with GFER mutation developed mild LV dysfunction without any structural or rhythmic changes at the age of 10 years. A 27-year-old man with YARS2-related mitochondrial disease had progressive hypertrophic cardiomyopathy with LV systolic dysfunction atrial dilatation (further details were described elsewhere ${ }^{18}$ ) that first identified in late childhood. A patient with a heterozygous TWNK variant was identified to have mild LV dysfunction when he was investigated for palpitations at the age of 26 years old. Interestingly, his grandmother (77 years old), mother ( 55 years old) and brother (27 years old) who also harboured the same TWNK variant did not exhibit any cardiac involvement.

Seven patients developed cardiac diseases that were deemed unrelated to their genetic defect: $P O L G(\mathrm{n}=1)$, TWNK $(\mathrm{n}=3)$ and RRM2B $(\mathrm{n}=3)$. The mean onset of cardiac abnormalities identified in these patients was $55.1 \pm 8.9$ years (95\% CI 46.9 to 63.4 ). Four patients had had a myocardial infarction secondary to coronary artery disease $(R R M 2 B=3 ; P O L G=1)$. The therapeutic interventions for three $R R M 2 B$ patients included emergency coronary angioplasty $(\mathrm{n}=1)$, implantable cardioverter defibrillator for prolonged non-sustained VT and moderate $\mathrm{LV}$ dysfunction at age 60 years $(\mathrm{n}=1)$, and elective coronary artery bypass surgery $(n=1)$. The patient with POLGrelated mitochondrial disease had persistent AF refractory to multiple ablations and subsequently had an acute admission due to myocardial infarction. Two cases of TWNK mutation had asymptomatic, mild LV dysfunction at age 43 and 57 years which remained stable for 11 years and 4 years of FU, respectively. Another TWNK case had asymptomatic LBBB detected at the age of 65 years. Overall, the frequencies of cardiac abnormalities within 


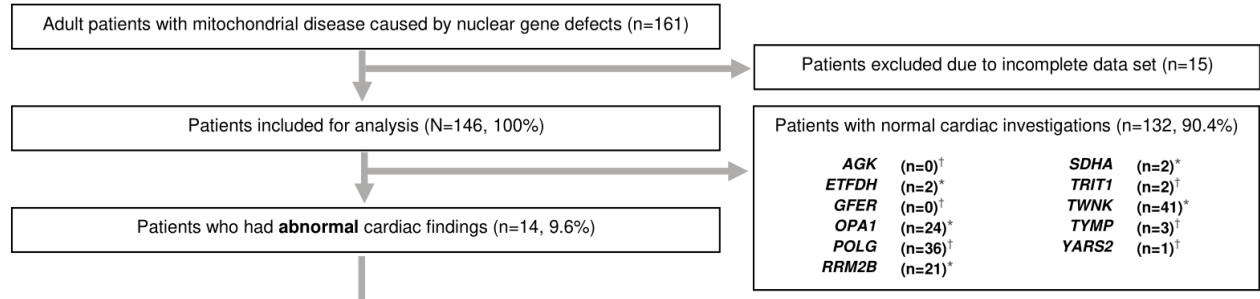

\begin{tabular}{|c|c|c|c|c|c|c|c|}
\hline \multicolumn{8}{|c|}{ Cardiac abnormalities related to the underlying mitochondrial disease $(n=7,4.8 \%)$} \\
\hline Gene & \multicolumn{2}{|c|}{$A G K(\mathrm{n}=2)$} & \multicolumn{3}{|c|}{ GFER $(n=3)$} & \multirow{2}{*}{$\frac{\text { YARS2 }(\mathrm{n}=1)}{M}$} & \multirow{2}{*}{$\frac{\text { PTWNK (n=1) }}{M}$} \\
\hline Gender & M & M & $\mathrm{M}$ & M & M & & \\
\hline Current age (years) & 21 & 22 & 35 & 32 & 22 & 27 & 27 \\
\hline $\begin{array}{c}\text { Age of cardiac } \\
\text { diagnosis (years) }\end{array}$ & 0 & 1 & 30 & 28 & 10 & 8 & 26 \\
\hline NMDAS cardiac score & 5 & 5 & 3 & 2 & 2 & 3 & 3 \\
\hline $\begin{array}{c}\text { Total scaled } \\
\text { NMDAS score } \\
\end{array}$ & $n / a$ & $n / a$ & 12.4 & 6.7 & 48.3 & 35.2 & 4.1 \\
\hline Risk factors for CVD & None & None & Sm & None & $\mathrm{Htn}, \mathrm{Ob}$ & $\mathrm{Htn}, \mathrm{Sm}$ & None \\
\hline MI secondary to CAD & No & No & No & No & No & No & No \\
\hline $\begin{array}{c}\text { Left ventricular } \\
\text { hypertrophy }\end{array}$ & Severe & Severe & Yes & Yes & No & Yes & No \\
\hline $\begin{array}{l}\text { Left ventricular } \\
\text { dysfunction }\end{array}$ & Severe & Severe & No & No & Mild & Mild & Mild \\
\hline $\begin{array}{l}\text { Stage IV (end-stage) } \\
\text { cardiomyopathy }\end{array}$ & Yes & Yes & No & No & No & No & No \\
\hline Other abnormalities & None & WPW & LBBB & $\mathrm{BFB}$ & None & None & None \\
\hline $\begin{array}{l}\text { Current cardiac } \\
\text { medication }\end{array}$ & $\begin{array}{l}\text { None post- } \\
\text { transplant }\end{array}$ & $\begin{array}{l}\text { None post- } \\
\text { transplant }\end{array}$ & ACEi & ACEi,BB & $\begin{array}{l}\text { ACEi, } \\
\text { CCB }\end{array}$ & ACEi & ACEi \\
\hline Invasive intervention & LVAD & $\begin{array}{l}2 \text { ablations, } \\
\text { LVAD }\end{array}$ & None & None & None & None & None \\
\hline Cardiac transplant & Yes, 13 yrs & Yes, 13 yrs & No & No & No & No & No \\
\hline
\end{tabular}

\begin{tabular}{|c|c|c|c|c|c|c|}
\hline \multicolumn{7}{|c|}{ Cardiac abnormalities not related to the underlying mitochondrial disease $(n=7,4.8 \%)$} \\
\hline \multirow{2}{*}{$\frac{P O L G(n=1)}{M}$} & \multicolumn{3}{|c|}{$\operatorname{RRM} 2 B(n=3)$} & \multicolumn{3}{|c|}{$T W N K(n=3)$} \\
\hline & M & M & $\mathrm{F}$ & $\mathrm{F}$ & $\mathrm{F}$ & $\mathrm{F}$ \\
\hline 70 & 67 & 83 & 71 & 54 & 76 & 61 \\
\hline 55 & 57 & 44 & 65 & 43 & 65 & 57 \\
\hline 4 & 4 & 3 & 2 & 3 & 2 & 2 \\
\hline 24.9 & 41.4 & 32.2 & 34.3 & 32.1 & 43.5 & 9.7 \\
\hline Htn, Lpd & Htn & Htn, Lpd & Htn & DM & None & None \\
\hline Yes & Yes & Yes & Yes & No & No & No \\
\hline Yes & Yes & Yes & No & No & No & No \\
\hline Mild & Moderate & Moderate & No & Mild & No & Mild \\
\hline No & No & No & No & No & No & No \\
\hline AF & NSVT & None & $\begin{array}{c}\mathrm{QTc} \\
>500 \mathrm{~ms}\end{array}$ & None & LBBB & None \\
\hline$B B, A R B$ & ACEi, BB & ARB, BB & ACEi, CCB & BB & None & ACEi \\
\hline $\begin{array}{l}\text { Ablation - } \\
\text { multiple }\end{array}$ & $\begin{array}{c}\text { Insertion } \\
\text { of ICD }\end{array}$ & $\begin{array}{c}\text { CABG for } \\
\text { CAD }\end{array}$ & $\begin{array}{l}\text { Four stents } \\
\text { for CAD }\end{array}$ & None & None & None \\
\hline No & No & No & No & No & No & No \\
\hline
\end{tabular}

Figure 1 Summary of cardiac abnormalities identified. Left ventricle dysfunction defined as mild (LVEF $45 \%-55 \%$ ), moderate $(35 \%-45 \%)$ and severe $(<35 \%)$. NMDAS cardiac score $<3$ indicates asymptomatic cardiac abnormalities. Other cardiac abnormalities includes conduction and repolarisation conditions. ?=thelink between the underlying genetic with cardiac abnormalities is tentative. ${ }^{*}$ The inheritance pattern is autosomal dominant for all cases of TWNK, RRM2B, OPA1 and SDHA except one RRM2B patient who has two pathogenic variants inherited as a recessive disease. $†$ The inheritance pattern is autosomal recessive for the following nDNA defects: POLG (except one case with a single heterozygous variant inherited as a dominant disease), GFER, YARS2, TYMP, ETFDH, TRIT1 and AGK. AF, atrial fibrillation; ARB, angiotensin receptor blocker; $\mathrm{BB}$, beta-blocker; BFB, bifasicular block; CABG, coronary artery bypass graft; $\mathrm{CCB}$, calcium channel blocker; CAD, coronary artery disease; CM, cardiomyopathy; CVD, cardiovascular disease; DM, diabetes mellitus; Htn, hypertension; ICD, implantable cardioverter defibrillator; Lpd, dyslipidaemia; LVAD, left ventricular assist device; Ob, obesity; NMDAS, Newcastle Mitochondrial Disease Adult Scale; NSVT, non-sustained ventricular tachyarrhythmia; Sm, History of cigarette smoking; WPW, Wolff-

Parkinson-White syndrome.

each of these genotypes ( TWNK, POLG and RRM2B) were low even though they were accounted for the two-thirds of adult patients in our cohort. (figure 1).

The frequency of individual cardiovascular risk factors is summarised in table 1 . There was no significant association between specific nuclear gene defects and with any of the cardiovascular risk factors. Nineteen patients were treated with an 3-hydroxy-3-methyl-glutaryl-coenz yme A reductase inhibitor (statin); none reported worsening of myopathy, myalgia or other significant adverse side effects. Moreover, there was no significant difference in creatine kinase level between the patients receiving statins $(\mathrm{n}=19$; mean $263.1 \pm 249.8$ units/L) and patients not receiving statins $(\mathrm{n}=70$; mean $198.9 \pm 213$ units/L) $(\mathrm{p}=0.265)$.

None of the patients with the following genetic defects developed cardiac abnormality during the FU: OPA1 (mean age $51.9 \pm 15.4$ years, mean FU $9.2 \pm 4.4$ years), TYMP (mean age $35.0 \pm 6.2$ years, mean FU $3.7 \pm 1.5$ years), ETFDH (mean age 43.5 \pm 17.7 years, mean FU 18.5 \pm 10.6 years), SDHA (mean age $82 \pm 8.5$ years, mean FU 17.5 \pm 9.2 years) and TRIT1 (mean age $32.5 \pm 5.0$ years, mean $\mathrm{FU}$ $9.5 \pm 2.1$ years $)$.

\section{DISCUSSION}

In this observational cohort study of adult patients with mitochondrial disease, we show that the majority of patients with nDNA pathogenic variants have normal cardiac studies. Abnormal cardiac findings were identified in approximately $10 \%$ of the patients and half of those with cardiac abnormalities had already presented before adulthood. In contrast, patients with pathogenic mtDNA variants have a significantly higher prevalence of cardiac involvement $(25 \%-50 \%) .{ }^{3419}$

Our findings of early-onset cardiac involvement caused by pathogenic $A G K$ and YARS2 variants are consistent with the published data. ${ }^{18} 20$ The clinical presentation of two $A G K$ cases exhibited classic features of Sengers syndrome $^{21}$ characterised by congenital cataracts, hypertrophic cardiomyopathy, myopathy and exercise intolerance. We previously demonstrated that hypertrophic cardiomyopathy is common among patients who harboured the pathogenic YARS2 variants, in addition to other clinical findings such as lactic acidosis, proximal myopathy, respiratory muscle weakness and sideroblastic anaemia in some cases. ${ }^{18}$ The exact function of GFER 
(Growth Factor, Augmenter of Liver Regeneration) protein is not well understood. The GFER genetic defect was initially reported in three children who presented with developmental delay, progressive myopathy, congenital cataracts and sensorineural hearing loss. ${ }^{22}$ In comparison, we describe three adult patients with recessive GFER variants from two unrelated pedigrees, who developed mild LV dysfunction; thus, expanding the phenotypic spectrum of GFER-related mitochondrial disease.

We identified mild LV dysfunction in one patient aged 27 years who harbours a heterozygous $T W N K$ variant that was investigated for intermittent palpitations. However, cardiac investigations were normal in three of his family members, who have the same genetic mutation. Nonspecific cardiac abnormalities were identified through routine screening in three other $T W N K$ patients over the age of 50 years, and they have coexisting cardiovascular risk factors. There is no evidence of cardiac phenotype in the TWINKLE deletor mouse model, ${ }^{23}$ and autosomal dominant TWNK mitochondrial disease typically associated with late-onset CPEO and mild myopathy in human.
As such, we believe that the risk of early cardiac disease is low in this patient group. ${ }^{24}$

Several nuclear genes involved in the mtDNA maintenance such as POLG, TWNK, RRM $2 B$ and $O P A 1$ account for a substantial proportion of the genetic diagnoses in adult patients. Our results suggest that these common nuclear gene defects do not have an inherent cardiac phenotype apart from a single case of TWNK mutation. Based on our longitudinal data, we have proposed a clinical algorithm of cardiac screening for $\mathrm{nDNA}$ related mitochondrial disease in adults (figure 2). A baseline cardiac screening is recommended for any novel or ultra rare nuclear gene defects with limited natural history data on their respective cardiac involvement.

A small number of older patients with cardiovascular risk factors developed coronary artery disease similarly seen in the general population, suggesting that the conventional management of cardiovascular risk factors should be instigated accordingly. There is a theoretical concern that using statins could exacerbate myopathy in patients with neuromuscular and mitochondrial

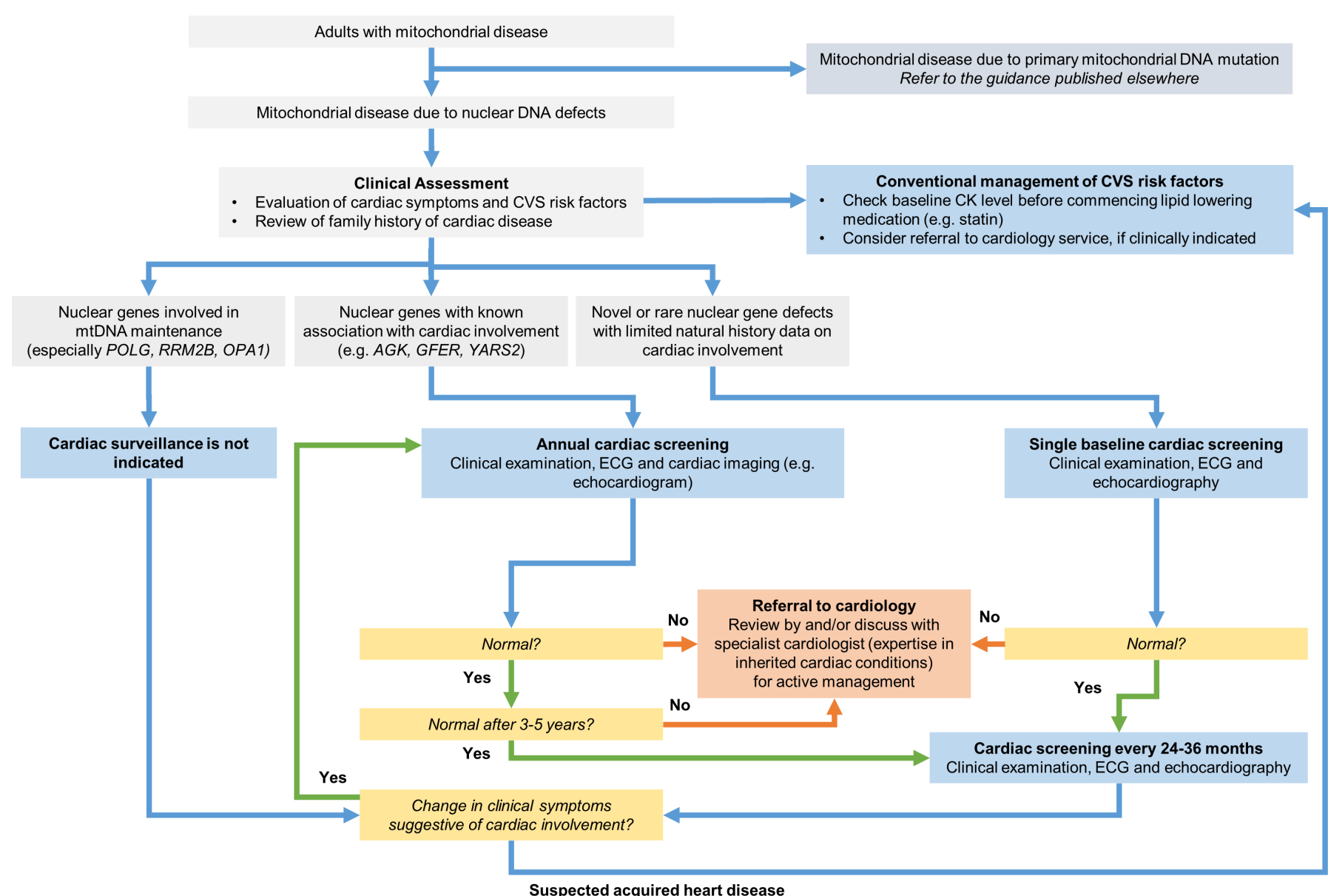

Figure 2 Clinical algorithm to guide cardiac surveillance for the adult mitochondrial disease of nuclear gene defects. This algorithm is proposed guidance and is not intended to replace the clinical judgement of healthcare professionals in the context of individual circumstances. The clinical guidelines for mitochondrial DNA mutations have been published. ${ }^{3}$ Clinical team refers to clinicians who regularly follow-up the patients with mitochondrial disease, and they include general neurologists, clinical geneticists, metabolic medicine physicians and general practitioners/primary care physicians. CK, creatine kinase; CVS, cardiovascular system. 
diseases. ${ }^{25}{ }^{26}$ However, we have not observed any significant adverse effect of statin use in our patients.

We have not been able to determine the risk of cardiac disease in rarer nuclear gene defects associated with the mtDNA maintenance such as MGME1, DNA2, SLC25A4 (also known as ANT1), DGUOK and MPV17.27 The published literature has not revealed that cardiac involvement is a consistent finding in these patients who presented with $\mathrm{CPEO}$ and multiple mtDNA deletions on muscle biopsy. ${ }^{28}{ }^{29}$ However, robust systematic evaluation of the risk of cardiac disease in these genes is warranted to inform clinical practice.

A few recent studies proposed that cardiac surveillance for mitochondrial patients can be stratified based on the clinical syndrome or phenotype alone. ${ }^{78}{ }^{30}$ However, such recommendations have limitations, given that the phenotype-genotype correlation is not always evident. For instance, CPEO and myopathy are common clinical features seen in adult patients with mitochondrial disease and the genetic causes are highly heterogeneous, which include primary mtDNA point mutations such as $\mathrm{m} .3243 \mathrm{~A}>\mathrm{G}$, single, large-scale mtDNA deletions or multiple mtDNA deletions secondary to nuclear gene defects as outlined previously. ${ }^{2731} 32$ If cardiac surveillance were to perform in all patients with CPEO or myopathy, a significant portion of patients with nDNA pathogenic would subject for unnecessary investigations and hospital visits.

There are several limitations in this study. First, we only capture three nuclear genes associated with an earlyonset cardiac phenotype in this cohort, and the patients have survived into adulthood. However, there are ultrarare nuclear genetic defects, such as aminoacyl-tRNA synthetase $^{33}$ that can cause fatal cardiac disease in childhood. Second, most of our patients did not have cardiac MR imaging performed. Cardiac MR has a higher sensitivity for the detection of myocardial changes ahead of ventricular dysfunction over routine transthoracic echocardiography. ${ }^{34}$ However, the majority of our patients have had serial echocardiograms over long FU to reduce the likelihood of any clinically significant pathology. Third, we only studied the dominant form of mitochondrial disease for these genes: TWNK, RRM2B, OPA1 and SDHA. We had not recruited patients with the autosomal recessive disease who typically have a more severe phenotype, frequently manifesting in childhood and much less prevalent in the population. Finally, the numbers of patients with specific genotypes (eg, TRIT1 and SDHA) are small in our cohort, and an international, multicentre study would be necessary to establish their risk of cardiac involvement definitively.

\section{CONCLUSIONS}

The overall risk of early cardiac involvement in adult mitochondrial disease caused by nuclear gene defects is low $(4.8 \%)$, and is genotype specific. Our study provides evidence that routine cardiac screening is not indicated for most adult patients with nuclear gene-related mitochondrial disease.

Acknowledgements We are extremely grateful to our clinical specialist nurse (Alexandra Bright), data manager of the Mitochondrial Disease Patient Cohort (Doug Jerry) and staff of the National Health Service (NHS) Highly Specialised Mitochondrial Disease Service laboratory in Newcastle, and clinicians who refer patients to our clinical service.

Contributors DMT, RM, GSG and YSN conceived the idea and designed the study. AZL, DMJ and YSN carried out the data collection and performed the analysis. MGDB, AMS, J0, CF, MEF, JPB, DMT, RM, GSG and YSN had provided substantial acquisition of data and interpretation. J0, JPB and MGDB gave critical feedback on the cardiac data. AZL and YSN wrote the first version of the manuscript. All authors critically reviewed the manuscript and approved the final version of this manuscript.

Funding This work was supported by the Wellcome Centre for Mitochondrial Research (203105/Z/16/Z), Newcastle University Centre for Ageing and Vitality (supported by the Biotechnology and Biological Sciences Research Council and Medical Research Council L016354), UK National Institute for Health Research (NIHR) Biomedical Research Centre (BRC) for Ageing and Age-Related Disease award to the Newcastle UponOn Tyne Hospitals NHS Foundation Trust, NIHR, and the UK NHS Specialist Commissioners, which funds the Rare Mitochondrial Disorders of Adults and Children Diagnostic Service in Newcastle Upon0n Tyne (http://www.newcastlemitochondria.com/). This work also received infrastructure support from NIHR Biomedical Research Centre, Newcastle and North Tyneside Comprehensive Local Research Network. YSN holds an NIHR Clinical Lectureship in Neurology (CL-201601-003). AZL has a PhD studentship at the Wellcome Centre for Mitochondrial Research.

Disclaimer The views expressed are those of the authors and not necessarily those of the NHS, the NIHR, the BRC or the Department of Health.

Competing interests None declared.

Patient consent for publication Not required.

Ethics approval This study complied with the Declaration of Helsinki. The UK Mitochondrial Disease Patient Cohort: A Natural History Study and Patient Registry is approved by the ethics committee, NRES Committee North East - Newcastle \& North Tyneside 2 (REC Reference Number: 13/NE/0326).

Provenance and peer review Not commissioned; externally peer reviewed.

Data availability statement Data available on request due to privacy/ethical restrictions. Data of deidentified participants are available on request to the oversight committee of UK Mitochondrial Disease Patient Cohort: A Natural History Study and Patient Registry.

Open access This is an open access article distributed in accordance with the Creative Commons Attribution 4.0 Unported (CC BY 4.0) license, which permits others to copy, redistribute, remix, transform and build upon this work for any purpose, provided the original work is properly cited, a link to the licence is given, and indication of whether changes were made. See: https://creativecommons.org/ licenses/by/4.0/.

\section{ORCID iDs}

Albert Zishen Lim http://orcid.org/0000-0002-1321-8063

Gráinne S Gorman http://orcid.org/0000-0002-7585-3409

Robert McFarland http://orcid.org/0000-0002-8833-2688

Yi Shiau Ng http://orcid.org/0000-0002-7591-2034

\section{REFERENCES}

1 Gorman GS, Schaefer AM, Ng Y, et al. Prevalence of nuclear and mitochondrial DNA mutations related to adult mitochondrial disease. Ann Neurol 2015;77:753-9.

2 Brunel-Guitton C, Levtova A, Sasarman F. Mitochondrial diseases and cardiomyopathies. Canadian Journal of Cardiology 2015;31:1360-76.

3 Bates MGD, Bourke JP, Giordano C, et al. Cardiac involvement in mitochondrial DNA disease: clinical spectrum, diagnosis, and management. Eur Heart J 2012;33:3023-33.

4 Wahbi K, Bougouin W, Béhin A, et al. Long-term cardiac prognosis and risk stratification in 260 adults presenting with mitochondrial diseases. Eur Heart J 2015;36:2886-93. 
5 Limongelli G, Masarone D, Pacileo G. Mitochondrial disease and the heart. Heart 2017;103:390-8.

6 St-Pierre G, Steinberg C, Dubois M, et al. What the cardiologist should know about mitochondrial cardiomyopathy? Can J Cardiol 2019;35:221-4.

7 Quadir A, Pontifex CS, Lee Robertson H, et al. Systematic review and meta-analysis of cardiac involvement in mitochondrial myopathy. Neurol Genet 2019;5:e339.

8 Parikh S, Goldstein A, Karaa A, et al. Patient care standards for primary mitochondrial disease: a consensus statement from the mitochondrial medicine Society. Genet Med 2017;19. doi:10.1038/ gim.2017.107. [Epub ahead of print: 2707 2017].

9 Schaefer AM, Phoenix C, Elson JL, et al. Mitochondrial disease in adults: a scale to monitor progression and treatment. Neurology 2006;66:1932-4.

10 McFarland R, Taylor RW, Turnbull DM. A neurological perspective on mitochondrial disease. Lancet Neurol 2010;9:829-40.

11 Taylor RW, Pyle A, Griffin H, et al. Use of whole-exome sequencing to determine the genetic basis of multiple mitochondrial respiratory chain complex deficiencies. JAMA 2014;312:68-77.

12 Wharton G, Steeds R, Allen J, et al. A minimum dataset for a standard adult transthoracic echocardiogram: a guideline protocol from the British Society of echocardiography. Echo Res Pract 2015;2:G9-24.

13 , Elliott PM, Anastasakis A, et al, Authors/Task Force members. 2014 ESC guidelines on diagnosis and management of hypertrophic cardiomyopathy: the Task Force for the Diagnosis and Management of Hypertrophic Cardiomyopathy of the European Society of Cardiology (ESC). Eur Heart J 2014;35:2733-79.

14 Douglas PS, Carabello BA, Lang RM, et al. 2019 ACC/AHA/ASE key data elements and definitions for transthoracic echocardiography: a report of the American College of Cardiology/American heart association Task force on clinical data standards (writing Committee to develop cardiovascular endpoints data standards) and the American Society of echocardiography. Circ Cardiovasc Imaging 2019;12:e000027.

15 Kligfield P, Gettes LS, Bailey JJ, et al. Recommendations for the standardization and interpretation of the electrocardiogram. Part I: the electrocardiogram and its technology. A scientific statement from the American heart association electrocardiography and arrhythmias Committee, Council on clinical cardiology; the American College of cardiology Foundation; and the heart rhythm Society. Heart Rhythm 2007;4:394-412.

16 Goff DC, Lloyd-Jones DM, Bennett G, et al. 2013 ACC/AHA guideline on the assessment of cardiovascular risk: a report of the American College of Cardiology/American Heart Association Task Force on Practice Guidelines. Circulation 2014;129:S49-73.

17 Rothman KJ. Epidemiology: an introduction. Oxford university press, 2012.

18 Sommerville EW, Ng YS, Alston CL, et al. Clinical features, molecular heterogeneity, and prognostic implications in YARS2-related mitochondrial myopathy. JAMA Neurol 2017;74:686-94.

19 Hollingsworth KG, Gorman GS, Trenell MI, et al. Cardiomyopathy is common in patients with the mitochondrial DNA m.3243A $>\mathrm{G}$ mutation and correlates with mutation load. Neuromuscul Disord 2012;22:592-6.

20 Haghighi A, Haack TB, Atiq M, et al. Sengers syndrome: six novel AGK mutations in seven new families and review of the phenotypic and mutational spectrum of 29 patients. Orphanet $J$ Rare Dis 2014;9:1-12

21 Morava E, Sengers R, Ter Laak H, et al. Congenital hypertrophic cardiomyopathy, cataract, mitochondrial myopathy and defective oxidative phosphorylation in two siblings with Sengers-like syndrome. Eur J Pediatr 2004;163:467-71.

22 Di Fonzo A, Ronchi D, Lodi T, et al. The mitochondrial disulfide relay system protein GFER is mutated in autosomal-recessive myopathy with cataract and combined respiratory-chain deficiency. Am J Hum Genet 2009;84:594-604.

23 Tyynismaa $\mathrm{H}$, Mjosund KP, Wanrooij S, et al. Mutant mitochondrial helicase Twinkle causes multiple mtDNA deletions and a lateonset mitochondrial disease in mice. Proc Natl Acad Sci U S A 2005;102:17687-92.

24 Fratter C, Gorman GS, Stewart JD, et al. The clinical, histochemical, and molecular spectrum of PEO1 (Twinkle)-linked adPEO. Neurology 2010;74:1619-26.

25 Apostolopoulou M, Corsini A, Roden M. The role of mitochondria in statin-induced myopathy. Eur J Clin Invest 2015;45:745-54.

26 Mancini GBJ, Baker S, Bergeron J, et al. Diagnosis, prevention, and management of statin adverse effects and intolerance: Canadian consensus Working group update (2016). Canadian Journal of Cardiology 2016;32:S35-65

27 Sommerville EW, Chinnery PF, Gorman GS, et al. Adult-onset Mendelian PEO associated with mitochondrial disease. $J$ Neuromuscul Dis 2014;1:119-33.

28 El-Hattab AW, Scaglia F. Mitochondrial DNA depletion syndromes: review and updates of genetic basis, manifestations, and therapeutic options. Neurotherapeutics 2013;10:186-98.

29 Viscomi C, Zeviani M. MtDNA-maintenance defects: syndromes and genes. J Inherit Metab Dis 2017;40:587-99.

30 Pfeffer G, Mezei MM. Cardiac screening investigations in adultonset progressive external ophthalmoplegia patients. Muscle Nerve 2012;46:593-6.

31 Grady JP, Campbell G, Ratnaike T, et al. Disease progression in patients with single, large-scale mitochondrial DNA deletions. Brain 2014;137:323-34.

32 Orsucci D, Angelini C, Bertini E, et al. Revisiting mitochondrial ocular myopathies: a study from the Italian network. J Neurol 2017;264:1777-84.

33 Sissler M, González-Serrano LE, Westhof E. Recent advances in mitochondrial aminoacyl-tRNA synthetases and disease. Trends $\mathrm{Mol}$ Med 2017;23:693-708.

34 Marwick TH, Neubauer S, Petersen SE. Use of cardiac magnetic resonance and echocardiography in population-based studies: why, where, and when? Circ Cardiovasc Imaging 2013;6:590-6.

35 Bates MGD, Hollingsworth KG, Newman JH, et al. Concentric hypertrophic remodelling and subendocardial dysfunction in mitochondrial DNA point mutation carriers. Eur Heart $J$ Cardiovasc Imaging 2013;14:650-8. 